\title{
O FENÔMENO DA DROGA E OS DISPOSITIVOS DE CUIDADO EM SAÚDE: PERCEPÇÕES DE ADOLESCENTES ESCOLARES
}

\author{
GABE, K. M. 1; SILVEIRA, S. V.2; MACHADO, L. S3; FELDMANN, R. M.4; VIDAL, D5; TEIXEIRA, M. S6; CORRÊA, L. M7; \\ KRUG, S. B. F8; GARCIA, E. L.9.
}

PALAVRAS-CHAVE: Adolescência. Drogas. Dispositivos de cuidado. Promoção de Saúde.

\begin{abstract}
RESUMO
A problemática da droga vem sendo evidenciada por levantamentos e estudos como uma questão a ser trabalhada na adolescência, dado que é nessa fase da vida que se dá o primeiro contato com as drogas, além de ser um momento de intensas mudanças para o sujeito. Objetiva-se analisar os sentidos produzidos nas falas dos adolescentes sobre o fenômeno da droga e sobre os dispositivos de cuidado ofertados ao usuário. Trata-se de um estudo qualitativo do tipo pesquisa-intervenção, utilizando a técnica de grupos focais. Para isso foram realizados três encontros durante 3 semanas consecutivas com alunos de escolas públicas, contendo cerca de 15 alunos. A análise dos dados se ancorou nos pressupostos da análise dos sentidos proposta por Mary Jane Spink. Esse artigo refere-se aos resultados de 12 escolas abrangidas. Como dispositivos de cuidado, as internações em clínicas e comunidades terapêuticas e/ou hospitais foram as mais citadas $(n=7)$, os serviços da rede de saúde pública pouco citados $(n=4)$, seguidos pelos dispositivos pertinentes ao âmbito da segurança pública $(n=3)$. A territorialidade apresentou-se como fator de influência no que tange ao lugar que a droga ocupa nas subjetividades dos adolescentes. Conclui-se que os dispositivos de cuidado mais conhecidos são marcados pela lógica da abstinência e da segurança pública em detrimento dos serviços de saúde pública. Os programas preventivos devem compreender a adolescência como potência e primar por uma assistência integral que considere $o$ adolescente em toda sua complexidade.
\end{abstract}

\section{THE DRUG PHENOMENON AND THE HEALTH CARE DEVICES: PERCEPTIONS OF ADOLESCENT STUDENTS}

KEYWORDS: Adolescent. Drugs. Care devices. Health promotion.

\begin{abstract}
The drug issue has been highlighted by surveys and studies as a theme to be worked on in adolescence, since that is it at that stage that the first contact with the drugs occurs, besides being a moment of intense changes for the person. This study aim to analyze the produced meanings in adolescents speeches about the drug phenomenon and the care devices offered to the users. It is a qualitative study, intervention-research type, using the focal group technique. The groups were realized during three consecutives weeks with students of public schools, containing at most 15 teenagers at time. The data analysis is performed according to the method of producing meaning in compliance with the approach proposed by Mary Jane Spink. The results regard to 12 visited schools. As care devices, admissions in clinics and therapeutic communities and in hospitals were the most cited $(n=7)$; the public health services were less cited $(n=4)$, followed by the public security devices $(n=3)$. The territoriality presented itself as an influencing factor concerning the place that the drug occupies in the subjectivities of adolescents. In conclusion, the most known care devices are marked by the abstinence and the public security logic in detriment

${ }^{1}$ Acadêmica do Curso de Psicologia da Universidade de Santa Cruz do Sul. E-mail: k.mueller.gabe@gmail.com

2 Mestranda do Programa de Pós-Graduação em Promoção da Saúde (PPGPS) da Universidade de Santa Cruz do Sul.

${ }^{3}$ Enfermeira, Mestra em Desenvolvimento Regional e Doutora em Serviço Social, docente do Curso de Enfermagem e do Programa de PósGraduação em Promoção da Saúde (PPGPS) da Universidade de Santa Cruz do Sul. E-mail: skrug@unisc.br

4 Psicóloga, Mestra em Psicologia Clínica e Doutora em Psicologia Clínica, docente do Curso de Psicologia, do Programa de Pós-Graduação em Promoção da Saúde (PPGPS) e do Programa de Pós-Graduação em Psicologia (PPGPSI) da Universidade de Santa Cruz do Sul. E-mail: edna@unisc.br
\end{abstract}


of the public health services. Preventive programs must understand the adolescence as a power and prioritize a integral assistance that consider adolescent in all its complexity.

\section{INTRODUÇÃo}

Há 10 anos uma iniciativa intitulada "Projeto Santa Cruz Novos Rumos" reunia membros da comunidade e do governo do município de Santa Cruz do Sul para identificar e discutir demandas sociais da comunidade, assim como elencar possíveis caminhos a serem seguidos para alcançar soluções em relação a essas demandas. Mediante parceria com a Universidade de Santa Cruz do Sul (UNISC), a sociedade buscava respostas sobre a temática do crack; para tanto, desenvolveu-se a pesquisa intitulada "A Realidade do Crack em Santa Cruz do Sul”, que traçou um panorama do uso de crack na população. Dentre os resultados, além da constatação da prevalência do uso de drogas na idade adulta (19 a 32 anos), destacou-se o fato de que o primeiro contato com as drogas, sobretudo a maconha e o crack, se dava ainda na infância e adolescência (10 a 15 anos) nas proximidades das escolas, achado que foi ponto chave para a criação e desenvolvimento de uma nova linha de pesquisa (GARCIA, 2012). Esse diagnóstico local chamou atenção para a necessidade de voltar o olhar ao público adolescente, levando em consideração a complexidade impressa nessa fase da vida.

Ainda, dados mundiais e nacionais ratificam a importância de trabalhar com a temática. Segundo o Relatório Mundial sobre Drogas da Nações Unidas sobre Drogas e Crime (UNODC, 2019), 35 milhões de pessoas no mundo que sofrem de transtornos relacionados ao uso de drogas, sendo que somente uma a cada sete tem acesso ao tratamento. No Brasil, em 2017 foi publicado o III Levantamento Nacional Sobre o Uso de Drogas pela População Brasileira, que apontou que o uso de drogas aparece em ascendência na população adolescente e jovem adulta. Cabe ressaltar que aproximadamente sete milhões (34,3\%) dos indivíduos menores de 18 anos reportaram ter consumido álcool, sendo que 22,2\% consumiram nos 12 meses que antecederam o levantamento (BASTOS et al., 2017), destacando-se a venda e o consumo ilegal.

0 presente artigo visa apresentar os resultados parciais referentes ao reconhecimento e conhecimento de dispositivos de cuidado em saúde. Tal estudo se constitui como um recorte da pesquisa intitulada "Narrativas de adolescentes sobre drogas e os Serviços de Saúde Mental CAPSia e CAPSad: intersecções possíveis no contexto de Santa Cruz do Sul”, que buscou unir a demanda da comunidade de trabalhar a temática drogas com o público alvo de tais intervenções caracterizado em estudos pregressos (adolescentes). Para tanto, utiliza-se da metodologia qualitativa de pesquisa-intervenção e da técnica de grupos focais, em que os dados são produzidos

em conjunto com os adolescentes. Posteriormente, esses dados são analisados a partir dos escritos de Mary Jane Spink acerca da produção de sentidos pelo discurso.

\section{FUNDAMENTAÇÃO TEÓRICA}

Entende-se a adolescência como um período situado entre a infância e a vida adulta, havendo divergência na literatura entre a idade cronológica que marca o início e o fim dessa etapa. Nessa pesquisa, compreende-se a adolescência conforme o que dispõe o Artigo $2^{\circ}$ do Estatuto da Criança e do Adolescente (BRASIL, 1990, n.p.): “considera-se criança, para os efeitos desta Lei, a pessoa até doze anos de idade incompletos, e adolescente 
aquela entre doze e dezoito anos de idade". A origem da palavra adolescência provém do latim ad (a, para) e olescer (crescer), formando a palavra adolescere, que igualmente originou o vocábulo adoecer. Assim, etimologicamente a adolescência compreende um período de crescimento marcado por transformações potencialmente dolorosas (SILVA, 2007).

Por compreender um espaço cronológico de transição entre duas moradas, o sujeito adolescente vivencia modificações psíquicas, biológicas e sociais, tendo como principais tarefas a ressignificação da identidade e a afirmação de si perante a sociedade (AYUB, 2009). Nessa etapa há, portanto, uma mudança de protagonismo do sujeito, que passa a atuar diretamente na construção do seu próprio projeto de vida (MARTINS; ANDRADE; ALMEIDA, 2003). Para Aberastury e Knobel (1981) o adolescente nessa fase da vida precisa elaborar o luto diantes das perdas dos pais, da infância e consequentemente do corpo infantil. Além disso, percebe o mundo a sua volta e tem a difícil tarefa de tornar-se independente de seus pais, necessitando assim criar sua própria identidade, dando um rumo a sua vida (DOMINGUES; DOMINGUES; BARACAT, 2009).

Calligaris (2000) aponta que a adolescência é um estágio marcado por perdas, uma vez que se perde a graça da criança, que anteriormente assegurava amor e solicitude, para adentrar em um estado em que, ainda que a maturação corporal pareça evidente, não garante ao sujeito o lugar de adulto. Nessa morada compulsória, o adolescente pode experimentar sentimentos de solidão e incompreensão, buscando nos pares pertencimento e apoio (BOCK, 2007). Além disso, autores de recentes estudos evidenciam uma contradição de discurso dos adultos diante da subjetividade dos adolescentes, ora há um desejo de autonomia ideal dos jovens, ora se estabelece um lugar de dependência no qual repercute um sentimento de injustiça (PENNA, 2017).

A construção da adolescência como um estágio específico entre a infância e a vida adulta é recente, datando entre os anos de 1918 e 1939 (SILVA, 2007) e, a partir do momento em que passa a ser considerada uma etapa do ciclo vital, se articula com uma série de comportamentos negativos que passam a caracterizá-la perante a sociedade, transformando-na em uma fase considerada difícil e que deve ser superada (BOCK, 2007). Para Bock (2007), essa concepção retrata uma sociedade produtivista que enaltece a vida adulta como ideal, entendendo que é nessa etapa que os indivíduos se tornarão completos e prontos. Contudo, essa estigmatização da adolescência ignora as pluralidades culturais que formam a sociedade, bem como deslegitima o adolescente como sujeito de desejos e saberes. Para Calligaris (2000) deve-se prezar para que o adolescente ocupe um lugar na trama social, uma vez que esses "amam, estudam, brigam, trabalham. Batalham com seus corpos, que se esticam e se transformam" (p.8). Neste contexto, considera-se fundamental escutar os adolescentes nas suas diversas formas discursivas, valorizando o diálogo como metodologia, para que sejam possíveis identificar suas legítimas demandas, necessidades e desejos.

Como forma de marcar a transição entre a infância e a vida adulta, a sociedade adota rituais de passagem que mediam simbolicamente o adolescente e o meio (AYUB, 2009), sendo a droga um possível elemento veiculador da imagem de adulto independente. A literatura aponta que o uso de drogas permeia a história da humanidade, sendo possível identificar registros do uso de substâncias psicoativas há aproximadamente mil anos, ainda nas primeiras civilizações (FERNANDES; FUZZINATO, 2012). Entretanto, o aumento do consumo e o fato do primeiro contato com a droga se dar ainda na adolescência tem sido alvo de preocupações das instâncias governamentais e de saúde pública de diversos países (OMS, 2018, tradução nossa). Em relação ao álcool, a instituição aponta que seu uso reduz o autocontrole e reforça os comportamentos de 
risco, sendo responsável por ocasionar lesões, violência e mortes prematuras, assim como pode acarretar em problemas de saúde ao longo da vida. Além disso, o uso de substâncias está relacionado com altos índices de abandono escolar e com o rompimento dos laços sociais (BRASIL, 2004).

Em parceria com o Ministério da Educação e com o Ministério da Saúde, o Instituto Brasileiro de Geografia e Estatística (IBGE, 2016) realizou, em 2015, a $3^{\text {a }}$ edição da Pesquisa Nacional de Saúde do Escolar (PeNSE), que traçou o perfil das condições de saúde e hábitos de cerca de 2,6 milhões de adolescentes matriculados no $9^{\circ}$ ano do Ensino Fundamental. De acordo com a pesquisa, 55,5\% dos adolescentes participantes já haviam consumido pelo menos uma dose de bebida alcoólica alguma vez na vida, enquanto $9 \%$ relataram já terem feito uso de drogas ilícitas pelo menos uma vez na vida. Esses dados estão em consonância com o perfil de consumo em Santa Cruz do Sul, conforme pesquisa realizada em 2010 com usuários de crack do município, que ainda constatou que o contato com as substâncias costuma ocorrer nas proximidades das escolas (GARCIA et al., 2012).

0 fato de os adolescentes buscarem em seus pares a aceitação plena e o sentimento de pertencimento pode fazer com que sofram com a pressão do grupo, incorporando ideais e comportamentos normatizados pelos demais membros. Ademais, a marginalização dos adolescentes e a consequente falta de espaços que o valorizem em suas potencialidades corrobora para que se sintam incompreendidos, sentimento comum e eventualmente danoso dessa etapa do ciclo vital. Nesse sentido, os autores Moura, Monteiro e Freitas (2016, p. 1691) sinalizam que "tudo isso facilita para que a droga ocupe um lugar central na vida dos sujeitos, fazendo com que os seus problemas ou sentimentos sejam "silenciados'". Essas características da adolescência a tornam uma etapa especialmente vulnerável ao uso e abuso de álcool e outras drogas.

Tendo em vista o exposto anteriormente, mostra-se fundamental o trabalho com adolescentes escolares acerca da temática da droga e da drogadição, visando a prevenção ao uso e abuso de drogas e a promoção de saúde. Entende-se a promoção de saúde como uma maneira de pensar em estratégias de cuidado que atentem para as especificidades da temática da drogadição na adolescência, buscando promover o bem-estar desses indivíduos.

A utilização da escola como espaço propulsor de discussões é recomendada e amparada pela Organização Mundial da Saúde - OMS (2006), tendo em vista que a maioria dos adolescentes frequentam esse espaço e identificam-se com os pares, passando a pertencerem aos grupos. Além disso, a Política Nacional sobre Drogas, ao dispor sobre as medidas de prevenção que devem ser adotadas em território nacional, aponta a escola como um potente local para a realização de trabalhos nesse sentido (BRASIL, 2005).

\section{A CONSTRUÇÃo DE PERCURSOS METODOLÓGICOS}

A metodologia da pesquisa se centra na pesquisa-intervenção, caracterizada sobretudo pelo entendimento da influência do pesquisador naquilo que está sendo pesquisado. Essa metodologia surge a partir do rompimento com a ciência experimental clássica, ultrapassando as paredes de laboratórios para aproximarse do cotidiano daquilo que se pesquisa. Pesquisar-intervindo significa conceber o ser humano em toda sua complexidade e integralidade, entendendo a impossibilidade de dissociar objeto investigado e sujeito que investiga (PAULON; ROMAGNOLI, 2010). Além disso, propõe a constante reflexão do pesquisador acerca de suas práticas, num processo de análise de implicação (PAULON; ROMAGNOLI, 2010; AMADOR; LAZZAROTO; SANTOS, 
2015). Igualmente pressupõe que não é possível haver investigação sem haver intervenção, dado que até mesmo o fazer indagações altera, em diferentes níveis, o ambiente e as pessoas que circulam nesse espaço (SZYMANSKI; CURY, 2004).

0 presente estudo aprovado pelo Comitê de ética em Pesquisa - UNISC, sob o CAAE no. 60589116.0.0000.5343 e tem como fonte financiadora o Programa para Pesquisa para o SUS (PPSUS) / FAPERGS. Essa escrita trata-se de um recorte resultante de marcadores identificados nos grupos focais realizados em doze escolas públicas do município de Santa Cruz do Sul com adolescentes de 12 a 18 anos, no período de maio de 2018 a agosto de 2019, totalizando aproximadamente 130 escolares.

A produção de dados se dá a partir da execução de grupos focais com os adolescentes, sendo realizados um encontro por semana durante três semanas consecutivas com cada grupo. Em cada grupo participaram cerca de 15 estudantes, que receberam e entregaram devidamente preenchidos e assinados o Termo de Consentimento Livre e Esclarecido e o Termo de Assentimento do Menor Incapacitado. A técnica de grupos focais propicia a circulação da palavra e a discussão entre os participantes e a horizontalidade do conhecimento, estando em conformidade com as novas práticas de educação em saúde, que "tem se deslocado da perspectiva do indivíduo para o do grupo social e da educação calcada em conteúdos e das abordagens universais para a educação centrada na perspectiva cultural dos seus possíveis beneficiários" (CARLINI-COTRIM, 2004, p. 286).

No primeiro encontro é feita a apresentação da pesquisa, dos pesquisadores e dos adolescentes, bem como realizam-se as combinações acerca do andamento dos encontros e esclarecimento de possíveis dúvidas. Em seguida os integrantes são divididos em pequenos grupos para a confecção de um cartaz alusivo ao tema da droga, sendo disponibilizado para tanto materiais para desenho e pintura, revistas para recorte, tesoura e cola. Essa técnica denomina-se "brainstorming" ou "chuva de ideias", tendo como pergunta disparadora "o que é droga para você"?

No segundo encontro os participantes são convidados a apresentar para o grande grupo os cartazes que produziram, justificando a escolha de cada item colocado. Esse momento de discussão com o coletivo busca a compreensão dos sentidos produzidos pelos adolescentes sobre a temática da droga, propiciando a tomada de consciência e reflexão acerca do assunto. Por fim, o terceiro encontro destina-se à pintura de um grande tecido disponibilizado pelos pesquisadores, em que os adolescentes podem elaborar um desenho e/ou uma escrita alusiva ao que foi trabalhado e discutido nos encontros anteriores. 0 material artístico confeccionado nas escolas é posteriormente exposto no Fórum de Discussão Sobre Drogas que ocorre anualmente na Universidade.

Ao encerrar as atividades em cada escola os pesquisadores reúnem-se para a produção de um diário de campo, que posteriormente é compartilhado com o restante do grupo de pesquisa. São realizados encontros semanais para discussão e análise dos dados produzidos nos grupos focais, assim como, para o planejamento das próximas intervenções. A análise dos dados é feita à luz dos escritos de Mary Jane Spink no que diz respeito a produção de sentidos através da linguagem. Para a autora o sentido de algo sempre é uma construção social que resulta da interação entre duas pessoas, uma vez que aquilo que é falado está sempre endereçado a uma outra pessoa e vice-versa (SPINK, 2010). Sendo assim, o sentido das coisas pode ser conhecido através da análise dos discursos, tendo em vista que o discurso é o meio de produção de realidades (SPINK; GIMENES, 1994).

\section{RESULTADOS E DISCUSSÃO}


Conforme exposto anteriormente, os resultados aqui explanados advém de um recorte da pesquisa que possibilitou a identificação, nos grupos focais, de um marcador denominado "dispositivos de cuidado em saúde". Ressalta-se que, em todas as escolas, os adolescentes participantes apresentaram senso crítico e capacidade reflexiva no que diz respeito ao conceito de droga, fatores de risco, fatores protetivos e dos impactos da drogadição na vida dos sujeitos. A capacidade crítica também foi evidenciada através da ampliação do conceito de droga, que não se limitou ao que é pré-concebido e pré-classificado como lícito ou ilícito, mas expandiu-se abarcando substâncias como o café, o refrigerante, o chocolate, as medicações e até mesmo as novas tecnologias, como o smartphone. Para esse entendimento, referiram que a droga é tudo aquilo que presume ou cause alguma relação de vício e que, portanto, esses itens poderiam ser caracterizados como drogas. Houveram também discussões sobre as nuances que se estabelecem entre a licitude e a ilicitude de substâncias, refletindo acerca da nocividade de drogas que são permitidas por lei, como o álcool e o cigarro.

Contudo observou-se que, no que tange aos dispositivos de cuidado ao usuário de álcool e outras drogas, houve pouca menção aos serviços da rede de saúde pública: dos doze grupos focais realizados, sete mencionaram a internação em clínicas terapêuticas e/ou hospitais; quatro citaram a religião; quatro grupos fizeram referência a algum serviço de saúde e três apontaram dispositivos do âmbito da segurança como medida de cuidado. Dessa forma, despontam dois grandes pontos de discussão: "o cuidado ao usuário de álcool e outras drogas: a quem pertence? " e "as drogas e a rede de saúde pública: intersecção necessária".

\section{0 cuidado ao usuário de álcool e outras drogas: a quem pertence?}

Historicamente, a temática das drogas vem sendo tratada sob um enfoque proibicionista e de guerra às drogas (CASELA et al., 2014; NOTO; GALDURÓZ, 1999; NUNES et al., 2010). A primeira norma proibitiva quanto ao consumo de substâncias ocorreu ainda no início do século XVII e, com o aumento do consumo de ópio no mundo, incentivou a criação de leis semelhantes sob a ótica da incriminação do sujeito (TORCATO, 2016). Para Fiore (2012) denomina-se proibicionismo o paradigma referente à atuação do Estado sob algumas substâncias, que se sustenta a partir de duas premissas fundamentais: "o consumo de drogas é uma prática prescindível e danosa, o que justifica sua proibição pelo Estado" (p.10) e "a atuação ideal do Estado para combater as drogas é criminalizar sua circulação e seu consumo" (p. 11).

Através da análise dos dados produzidos, foi possível identificar que, dentre os participantes da pesquisa, a questão da drogadição está intrinsecamente vinculada à ilegalidade e à criminalidade, sendo percebida muito mais como uma temática pertencente ao âmbito da segurança pública do que ao âmbito da saúde. Pode-se relacionar tal dado à disponibilidade de informações, que na maioria das vezes, são veiculadas pelos canais de comunicação, relacionando o uso de drogas diretamente com a violência e a criminalidade.

Souza (2016), pesquisador de referência no âmbito da Política Nacional sobre Drogas, ressalta que a sociedade juntamente com a mídia sensacionalista divulga cenas do uso explícito de drogas em determinados locais para cobrarem medidas governamentais de combate ao problema. Tal atividade apavora a população e provoca a criação de um estigma ao usuário de crack, o "cracrudo", que passa a ser visto apenas como um indivíduo incapaz, imprestável, inclinado à prática de crimes, assumindo culpas pelos infortúnios coletivos. 
Observa-se que essa estigmatização do usuário não se firma exclusivamente no que diz respeito ao crack, ampliando-se em direção às demais drogas ilícitas.

Para muitos adolescentes, o fenômeno da droga pertence e atravessa seus cotidianos, estabelecendo o modo como as relações se dão nos territórios em que habitam. 0 tráfico de drogas foi mencionado em todas as escolas, sendo que nas zonas periféricas assumiu papel de destaque, fazendo-se presente nas diferentes esferas em que transitam: familiar, comunitária e social. Para esses sujeitos, baseado nas conclusões que suas próprias vivências oferecem, o envolvimento com o tráfico resulta em apenas dois caminhos: a morte ou a prisão. Dessa forma, entende-se que a violência gerada pelo abuso de substâncias e pelo tráfico de drogas indica estar relacionada com o aparecimento desse marcador.

Ainda que compreendam a complexidade da drogadição, em seus discursos nota-se que a droga traduz o conceito simbólico do mal, estando fortemente associada a um embate moral e de valores. Para Nunes et al. (2010) essa associação reflete os princípios propagados pela cultura judaico-cristã através dos séculos, em que a droga relaciona-se com vícios e os prazeres e, portanto, com o pecado. Sendo assim, na atualidade, os usuários de drogas por vezes são considerados desviantes e têm suas histórias como exemplo das "escolhas erradas". Corroborando essa afirmação, uma adolescente, ao discorrer sobre a temática, aponta que a compreensão da droga como algo errado pode atuar como fator protetivo para o uso de substâncias: "alguém tem que dizer que é errado" (sic). Baseado nessas premissas, historicamente o tratamento ao usuário esteve subjugado às instâncias religiosas e, posteriormente, ao modelo biomédico; como consequência, tornou-se segregador, reducionista e repressivo (BRASIL, 2004; NUNES et al. 2010; PASSOS, 2010; ROMANINI; DETONI, 2014).

Nos grupos focais, quando questionados sobre os locais em que os usuários poderiam buscar ajuda, esse modelo mostrou-se predominante: sete dos doze grupos mencionaram a internação em clínicas terapêuticas e/ou hospitais; quatro citaram a Igreja e a inserção em grupos religiosos e quatro grupos referiram algum serviço de saúde pública. As internações psiquiátricas e o envolvimento com a religião pressupõem que o tratamento tenha como única finalidade possível a abstinência. Sobre o paradigma da abstinência, Passos (2011, p. 157) define:

\footnotetext{
"Por paradigma da abstinência entendemos algo diferente da abstinência enquanto uma direção clínica possível e muitas vezes necessária. Por paradigma da abstinência entendemos uma rede de instituições que define uma governabilidade das políticas de drogas e que se exerce de forma coercitiva na medida em que faz da abstinência a única direção de tratamento possível, submetendo o campo da saúde ao poder jurídico, psiquiátrico e religioso."
}

Nesse sentido, a lógica da abstinência reproduz o modelo binarista e rigidamente definido com que a temática do abuso de álcool e outras drogas é pensada: a partir de comportamentos antissociais ou criminosos. Por conseguinte, as ações pensadas para alcançar esse objetivo ora envolvem as instâncias de segurança pública - através da redução da oferta de drogas -, ora envolvem as instâncias de saúde no modelo psiquiátrico tradicional - redução da demanda por meio da internação. Ambas implicam o afastamento total do usuário com o agente indutor, ou seja, com a droga (BRASIL, 2004). Ainda nesse âmbito, um grupo de adolescentes citou a melhora no policiamento como dispositivo de cuidado ao usuário.

As drogas e a rede de saúde pública: intersecção necessária 
Buscando romper com a associação da temática da drogadição à criminalidade, a Política do Ministério da Saúde para a Atenção Integral a Usuários de Álcool e outras Drogas considera essa questão como uma problemática de saúde pública, assumindo o compromisso de prevenir, tratar e reabilitar o fenômeno da droga e da drogadição de forma integral (BRASIL, 2004). Para tanto, e cumprindo com os preceitos do SUS, utiliza-se dos diferentes níveis de atenção, abrangendo a atenção básica, a atenção especializada, a atenção hospitalar e as redes de suporte social. As diretrizes que regem a Política operam à luz da perspectiva de redução de danos e prezam pela reabilitação do usuário e pela sua reinserção social (CORTES et al., 2014). Entende-se a redução de danos (RD) como uma forma de cuidado alternativa ao paradigma da abstinência, diferenciando-se deste sobretudo no que diz respeito ao olhar direcionado ao usuário: enquanto a última centra suas práticas em tratamentos autoritários, a RD busca estimular que o sujeito assuma posição ativa quanto a seu próprio tratamento (GARCIA et al, 2019).

Nos grupos focais, quatro dos doze grupos realizados fizeram menção a rede de saúde como dispositivo de cuidado: três mencionaram a atenção especializada, representada pelos Centro de Atenção Psicossocial e um fez menção à atenção básica, representada pelos Agentes Comunitários de Saúde das Estratégias Saúde da Família (ESF). Cortes et al. (2014) afirmam que, apesar dos esforços para que as equipes de atenção básica atuem no sentido de prevenir o uso de drogas nos territórios em que estão inseridas, observa-se uma defasagem nessa atuação. Os autores ainda referem que por vezes os profissionais de saúde que integram os serviços sentem-se incapazes e impotentes para abordar essa temática (CORTES et al., 2014). Reiterando essas afirmativas, a pouca menção das instâncias de saúde pública e o desconhecimento dos adolescentes quanto ao funcionamento e a organização da rede indica estar associada com a falta de protagonismo dos serviços nos territórios no que concerne à temática da droga.

A literatura aponta que programas preventivos com adolescentes têm demonstrado importante potencial na redução do uso de substâncias por adolescentes (BARBOSA; PEREIRA; OLIVEIRA, 2014). No entanto, as ações tradicionais que usualmente ocorrem nas escolas têm sido alvo de críticas por serem entendidas como pontuais e descontínuas (CASELA et al., 2014), bem como por enfatizarem a perspectiva proibicionista e o paradigma da abstinência. Barbosa, Pereira e Oliveira (2014) referem que as medidas profiláticas a serem tomadas pelas equipes de saúde devem identificar os motivos que tornam a droga atraente para esse público, bem como entender de que forma essa temática vem sido tratada localmente. Nos encontros realizados, ressaltase que, embora as narrativas dos escolares se aproximem em alguns pontos, a territorialidade apresentou-se como agente significativo no que diz respeito ao lugar que a droga ocupa em suas subjetividades. Sendo assim, mostra-se necessário traçar um panorama do contexto de cada território e de sua comunidade a fim de criar as práticas de prevenção mais efetivas.

\section{CONCLUSÃO}

O uso e abuso de drogas configura-se como uma problemática de saúde pública e tem preocupado as instâncias governamentais, sobretudo no que diz respeito ao aumento do consumo de substâncias e ao primeiro contato com a droga se dar ainda na adolescência. 0 entendimento dessa etapa do ciclo vital como um período de busca pela consolidação da personalidade do jovem perante a sociedade ressalta a importância da oferta de 
espaços de discussão e reflexão com essa população. Reconhecer o adolescente em sua autenticidade e afirmalo enquanto sujeito ativo na construção de sua própria história de vida só é possível através de uma escuta atenta e acolhedora. Entende-se que para a formulação de estratégias eficazes de prevenção à drogadição é preciso antes de tudo compreender os sentidos que os próprios adolescentes produzem.

Os dispositivos de cuidado apontados pelos participantes da pesquisa relacionam-se majoritariamente com medidas que adotam a abstinência como único caminho possível no tratamento ao usuário de álcool e outras drogas, reproduzindo sua associação com a criminalidade e com o pecado. Partindo da premissa de que historicamente os recursos terapêuticos direcionados a essa população estiveram subjugados às instâncias religiosas e judiciárias, tratadas sob o modelo segregador asilar e hospitalocêntrico, mostra-se fundamental a realização de trabalhos com os escolares que abordem as diretrizes da nova política de saúde mental. Além disso o desconhecimento quanto a organização da rede assistencial reforça a necessidade de educação em saúde, visando propiciar o sentimento de pertença e corresponsabilidade dos adolescentes na construção de um cuidado horizontal e inclusivo.

Ressalta-se a urgência da elaboração de programas preventivos promovidos no âmbito comunitário pelos serviços de saúde e pelas escolas, sempre considerando as singularidades e especificidades de cada população. A heterogeneidade das maneiras com que o fenômeno da droga constitui os adolescentes enquanto sujeitos salienta a importância de os trabalhos preventivos não assumirem caráter totalizante e generalista. Ante o exposto, a presente pesquisa cumpre com seus objetivos ao convocar o jovem a expressar e compartilhar seus saberes, colocando-os não mais como meros receptores de informações, mas como sujeito protagonista. Sendo assim, a realização de atividades no espaço escolar que propiciem momentos de fala e de escuta constitui-se como uma intersecção possível e necessária entre a saúde e a educação, atuando em conjunto na prevenção ao uso e abuso de drogas e a promoção de saúde.

\section{AGRADECIMENTOS}

As autoras agradecem ao CNPq e a FAPERGS, pelo apoio financeiro, à UNISC e ao Programa de Pesquisa para o SUS (PPSUS) do Ministério da Saúde.

\section{REFERÊNCIAS}

ABERAStURY, A.; KNOBEL, M. Adolescência Normal. Porto Alegre: Artes Médicas, 1981. 92 p.

AMADOR, F. S.; LAZZAROTTO, G. D. R.; SANTOS, N. I. S. dos. Pesquisar-Agir, Pesquisar-Intervir, Pesquisar-Interferir / Search-Act, Search-Intervene, Search-Interfere. Revista Polis e Psique, Porto Alegre, v. 5, n. 2, p.228-248, 31 ago. 2015. ISSN 2238-152X. DOI: https://doi.org/10.22456/2238-152X.58180. Disponível em: < https://seer.ufrgs.br/PolisePsique/article/view/58180>. Acesso em: 12 fev. 2020.

AYUB, R. C. P. 0 olhar de psicanalistas que escutam a adolescência: singularidades da clínica atual. 2009.76 f. Dissertação (Mestrado) - Curso de Mestrado em Psicologia Clínica, Faculdade de Psicologia, Pontifícia Universidade Católica do Rio Grande do Sul, Porto Alegre, 2009 . Disponível em: < http://tede2.pucrs.br/tede2/bitstream/tede/699/1/421854.pdf >. Acesso em: 10 dez. 2020.

BARBOSA, A. J. G.; PEREIRA, C. E. S.; OLIVEIRA, J.C. Prevenção ao uso de drogas por adolescentes: intervenções que funcionam. In: RONZANI, T. M.; SILVEIRA, P. S. da (org.). Prevenção ao uso de álcool e outras drogas no 
contexto escolar. Juiz de Fora: UFJF, 2014. p. 39-48. Disponível em: < https://www.ufjf.br/crepeia/2014/11/10/livro-gratuito-prevencao-uso-alcool-drogas-contexto-escolar/>. Acesso em: 20 fev. 2020.

BASTOS, F.I.P.M., VASCONCELLOS, M.T.L.D., DE BONI, R.B., REIS, N.B.D, COUTINHO, C.F.D.S. III Levantamento Nacional Sobre 0 Uso De Drogas Pela População Brasileira. 2017. Rio de Janeiro: Fundação Oswaldo Cruz (FIOCRUZ) \& Secretaria Nacional de Políticas sobre Drogas (SENAD).

BRASIL. Lei n. 8.069, de 13 de julho de 1990. Dispõe sobre o Estatuto da Criança e do Adolescente e dá outras providências. Diário Oficial [da] República Federativa do Brasil, Brasília, DF, 14 jul. 1990. Disponível em: <http://www.planalto.gov.br/ccivil_03/leis/I8069.htm>. Acesso em: 03 dez. 2019.

BRASIL. Ministério da Saúde. Secretaria Executiva. Coordenação Nacional de DST/Aids. A política do Ministério da Saúde para atenção integral a usuários de álcool e outras drogas. Brasília: Ministério da Saúde, 2004. Disponível em: <http://bvsms.saude.gov.br/bvs/publicacoes/pns_alcool_drogas.pdf>. Acesso em: 04 fev. 2020.

BRASIL. Decreto $n^{\circ}$ 9.761, de 11 de abril de 2019. Aprova a Política Nacional sobre Drogas. Diário Oficial [da] República Federativa do Brasil, Brasília, DF, 12 abr. 2019.Disponível em <http://www.planalto.gov.br/ccivil_03/_ato2019-2022/2019/decreto/D9761.htm>. Acesso em: 10 fev. 2020.

BOCK, Ana Maria Bahia. A adolescência como construção social: estudo sobre livros destinados a pais e educadores. Psicologia Escolar e Educacional, Campinas, v. 11, n. 1, p.63-76, jun. 2007. ISSN 2175-3539. D0I: https://doi.org/10.1590/S1413-85572007000100007. Disponível em: <http://www.scielo.br/scielo.php?script=sci_arttext\&pid=S1413-85572007000100007>. Acesso em: 03 dez. 2019.

CALLIGARIS, Contardo. A adolescência. São Paulo: Publifolha, 2000. 83 p.

CARLINI-COTRIM, Beatriz. Potencialidades da técnica qualitativa grupo focal em investigações sobre abuso de substâncias. Revista de Saúde Pública, [online], v. 30, n. 3, p.285-293, jun. 1996. ISSN 0034-8910. DOI: http://dx.doi.org/10.1590/s0034-89101996000300013. Disponível em: <http://www.scielo.br/scielo.php?pid=S0034-89101996000300013\&script=sci_abstract\&tIng=pt>. Acesso em: 12 mar. 2020.

CASELA, A. L. M. et al. As práticas de prevenção ao uso de drogas no Brasil. In: RONZANI, T. M.; SILVEIRA, P. S. da (org.). Prevenção ao uso de álcool e outras drogas no contexto escolar. Juiz de Fora: UFJF, 2014. p. 39-48. Disponível em: <https://www.ufjf.br/crepeia/2014/11/10/livro-gratuito-prevencao-uso-alcool-drogas-contextoescolar/>. Acesso em: 20 fev. 2020.

CORTES, Laura Ferreira et al. Atenção a usuários de álcool e outras drogas e os limites da composição de redes. Revista Eletrônica de Enfermagem [online], v. 16, n. 1, p.84-92, mar. 2014. ISSN 1518-1944. D0I: http://dx.doi.org/10.5216/ree.v16i1.20279. Disponível em: <https://revistas.ufg.br/index.php/fen/article/view/20279>. Acesso em: 12 mar. 2020.

DOMINGUES, M. R. C.; DOMINGUES, T. L. C.; BARACAT, J. Uma leitura psicanalítica da adolescência: mudança e definição. Revista Científica Eletrônica de Psicologia [online], v. 1, n. 12, p.1-7, maio 2009. ISSN $1806-0625$. Disponível em: < http://faef.revista.inf.br/imagens_arquivos/arquivos_destaque/Q311xFKbubqXqki_2013-5-1312-49-37.pdf>. Acesso em: 12 mar. 2020>

FIORE, Maurício. 0 lugar do Estado na questão das drogas: o paradigma proibicionista e as alternativas. Novos Estudos - Cebrap, São Paulo, n. 92, p.9-21, mar. 2012. ISSN 0101-3300. DOI: http://dx.doi.org/10.1590/s010133002012000100002. Disponível em: <http://www.scielo.br/scielo.php?script=sci_arttext\&pid=S010133002012000100002>. Acesso em: 15 mar. 2020.

FERNANDES, V. R.; FUZINATTO, A. M. Drogas: proibição, criminalização da pobreza e mídia. In: $1^{\circ}$ Congresso Internacional de Direito e Contemporaneidade, 2012, Santa Maria. Anais... Santa Maria: UFSM, 2012. p. 1 - 11. Disponível em: <http://coral.ufsm.br/congressodireito/anais/2012/4.pdf>. Acesso em: 10 fev. 2020. 
GARCIA, Edna Linhares et al. Conhecendo o perfil do usuário de crack de Santa Cruz do Sul. Barbarói. v.36, ed. esp., p.83-95, 2012. ISSN 1982-2022. DOI: http://dx.doi.org/10.17058/barbaroi.v0i36.2922Disponível em: <https://online.unisc.br/seer/index.php/barbaroi/article/viewFile/2922/2106>. Acesso em: 02 fev. 2020.

GARCIA, Edna Linhares et al. Redução de danos: a construção do ato nômade e do cuidado compartilhado. Cesumar - Ciências Humanas e Sociais Aplicadas, Maringá, v. 24, n. 1, p.9-27, jan. 2019. Disponível em: <https://periodicos.unicesumar.edu.br/index.php/revcesumar/article/view/7165>. Acesso em: 18 mar. 2020.

INSTITUTO BRASILEIRO DE GEOGRAFIA E ESTATÍSTICA - IBGE. Pesquisa Nacional de Saúde do Escolar: 2015. Rio de Janeiro: IBGE, 2016. 132p. Disponível em: https://biblioteca.ibge.gov.br/visualizacao/livros/liv97870.pdf. Acesso em: 20 jul. 2020.

MARTINS, P. de 0.; TRINDADE, Z. A.; ALMEIDA, Â. M. de 0.0 ter e o ser: representações sociais da adolescência entre adolescentes de inserção urbana e rural. Psicol. Reflex. Crit., Porto Alegre, v. 16, n. 3, p. 555-568, 2003. ISSN 1678-7153. DOI: https://doi.org/10.1590/S0102-79722003000300014. Disponível em <http://www.scielo.br/scielo.php?script=sci_arttext\&pid=S0102-79722003000300014\&Ing=en\&nrm=iso>. Acesso em: 20 dez. 2019.

MOURA, N. A.de; MONTEIRO, M.R.A; FREITAS, R.J.M. de. Adolescentes usuários de drogas (I)lícitas e de violência. Revista de Enfermagem UFPE, v. 10, n. 5, 2016. ISSN 1981-8963. DOI: https://doi.org/10.5205/1981-8963v10i5a13543p1685-1693-2016. Disponível em: <https://periodicos.ufpe.br/revistas/revistaenfermagem/article/viewFile/13543/16313>. Acesso em: 09 fev. 2020.

NUNES, D. C. et al. “...outras palavras sobre o cuidado de pessoas que usam drogas...”. In: SANTOS, L. M. de B. (org.). Outras palavras sobre o cuidado de pessoas que usam drogas. Porto Alegre: Ideograf, 2010. p. 7-14. Disponível em: <http://www.crprs.org.br/publicacoes/outras-palavras-sobre-o-cuidado-de-pessoas-que-usamdrogas >. Acesso em: 28 fev. 2020.

NOTO, A. R.; GALDURÓZ, J. C F. O uso de drogas psicotrópicas e a prevenção no Brasil. Ciência \& Saúde Coletiva, Rio de Janeiro, v. 4, n. 1, p.145-151, 1999. ISSN 1413-8123. DOI: https://doi.org/10.1590/S141381231999000100012. Disponivel em: <http://www.scielo.br/scielo.php?pid=S141381231999000100012\&script=sci_abstract\&tlng=pt>. Acesso em: 28 fev. 2020.

ORGANIZAÇÃO MUNDIAL DA SAÚDE (OMS). Prevenção do suicídio: um manual para professores e educadores. Departamento de Saúde Mental, Genebra: OMS, $2006 . \quad$ Disponível em: <https://apps.who.int/iris/bitstream/handle/10665/66801/WHO_MNH_MBD_00.3_por.pdf;jsessionid=5E8AE 2C4352415185674DEED883E4953?sequence=5>. Acesso em: 02 fev. 2020.

ORGANIZAÇÃO MUNDIAL DA SAÚDE (OMS). Adolescentes: health risk and solutions. Fact sheets, [online], dez. 2018. Disponível em: <https://www.who.int/news-room/fact-sheets/detail/adolescents-health-risks-andsolutions>. Acesso em: 18 mar. 2020.

PASSOS, Eduardo. Pensar diferentemente o tema das drogas e o campo da saúde mental. In: SANTOS, L. M. de B. (org.). Outras palavras sobre o cuidado de pessoas que usam drogas. Porto Alegre: Ideograf, 2010. p. 7-14. Disponível em: <http://www.crprs.org.br/publicacoes/outras-palavras-sobre-o-cuidado-de-pessoas-que-usamdrogas>. Acesso em: 28 fev. 2020.

PASSOS, E.; SOUZA, T. P. Redução de danos e saúde pública: construções alternativas à política global de "guerra às drogas". Psicologia \& Sociedade, Florianópolis, v. 23, n. 1, p.154-162, abr. 2011. ISSN 1807-0310. D0I: http://dx.doi.org/10.1590/s0102-71822011000100017.

<http://www.scielo.br/scielo.php?script=sci_arttext\&pid=S0102-71822011000100017>. Acesso em: 12 mar. 2020.

PAULON, S. M.; ROMAGNOLI, R. C. Pesquisa-intervenção e cartografia: melindres e meandros metodológicos. Estudos e Pesquisas em Psicologia, Rio de Janeiro, v. 10, n. 1, p.85-102, jan. 2010. ISSN 18084281. DOI: https://doi.org/10.12957/epp.2010.9019. Disponível em: <https://www.epublicacoes.uerj.br/index.php/revispsi/article/view/9019/7455>. Acesso em: 12 fev. 2020. 
ROMANINI, M.; DETONI, P. P. A culpabilização como efeito do modo indivíduo de subjetivação nas políticas sociais. Revista Polis e Psique, Porto Alegre, v. 4, n. 2, p.206-229, 2014. ISSN 2238-152X. DOI: https://doi.org/10.22456/2238-152X.51093. Disponível

em: <https://seer.ufrgs.br/PolisePsique/article/view/51093>. Acesso em: 12 mar. 2020.

SILVA, Denise Regina Quaresma da. Mães-menininhas: a gravidez na adolescência escutada pela psicanálise e educação. 2007. 203 f. Tese (Doutorado) - Curso de Programa de Pós-graduação em Educação, Universidade Federal do Rio Grande do Sul, Porto Alegre, 2007. Disponível em: <https://www.lume.ufrgs.br/bitstream/handle/10183/14833/000669541.pdf?sequence=1>. Acesso em: 13 mar. 2020.

SOUZA, Jessé (Org.). Crack e exclusão social. Brasília: Ministério da Justiça e Cidadania. Secretaria. Nacional de

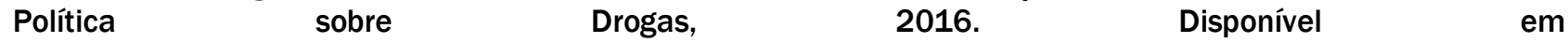
<https://repositorio.observatoriodocuidado.org/bitstream/handle/handle/561/Crack\%20e\%20exclus\%C3\%A3 o\%20social.pdf?sequence=1\&isAllowed=y>. Acesso em: 19 mar. 2020.

SPINK, Mary Jane. Linguagem e produção de sentidos no cotidiano. Rio de Janeiro: Centro Edelstein de Pesquisas Sociais, 2010. 72p. Disponivel em <https://static.scielo.org/scielobooks/w9q43/pdf/spink9788579820465.pdf>. Acesso em: 02 jan. 2020.

SPINK, M. J.; GIMENES, M. da G. G. Práticas discursivas e produção de sentido: apontamentos metodológicos para a análise de discursos sobre a saúde e a doença. Saúde e Sociedade, São Paulo, v. 3, n. 2, p.149-171, 1994. ISSN 0104-1290. DOI: https://doi.org/10.1590/S0104-12901994000200008. Disponível em: <http://www.scielo.br/scielo.php?script=sci_arttext\&pid=S0104-12901994000200008>. Acesso em: 20 dez. 2019.

SZYMANSKI, H.; CURY, V. E. A pesquisa intervenção em psicologia da educação e clínica: pesquisa e prática psicológica. Estudos de Psicologia, Natal, v. 9, n. 2, p.355-364, maio 2004. ISSN 1678-4669. D0I: https://doi.org/10.1590/S1413-294X2004000200018. Disponível em: <http://www.scielo.br/scielo.php?pid=s1413-294x2004000200018\&script=sci_abstract\&tIng=pt>. Acesso em: 12 fev. 2020.

TORCATO, Carlos Eduardo Martins. A história das drogas e sua proibição no Brasil: da Colônia à República. 2016. 371 f. Tese (Doutorado) - Curso de Programa de Pós-graduação em História Social, Universidade de São Paulo, São Paulo, 2016. Disponível em: <https://www.teses.usp.br/teses/disponiveis/8/8138/tde-05102016165617/pt-br.php>. Acesso em: 13 mar. 2020.

UNITED NATIONS OFFICE ON DRUGS AND CRIMES (UNODC). World drug report. Viena: United Nations, 2019. Disponível em: <https://wdr.unodc.org/wdr2019/>. Acesso em: 13 mar. 2020. 